$\xi=-1$

\title{
Experimental and numerical evaluations of Kirkuk field soil treated with waste shredded tire
}

\author{
Aram Mohammed Raheem * \\ Ph.D., Civil Engineering Department, University of Kirkuk, Kirkuk, Iraq \\ *Corresponding author E-mail: engaram@yahoo.com
}

\begin{abstract}
In this study, an experimental and numerical investigation of Kirkuk real field soil treated with waste tire has been examined. Field soil samples from Kirkuk city have been collected and tested experimentally to evaluate the basic soil properties. The field soil has been treated with waste shredded tires and up to $10 \%$. A series of direct shear tests under different normal stresses and unconfined compression tests with two different rates have been performed on both untreated and waste tire treated soils. For the untreated soil, the maximum shear stress measured by the direct shear test increased by $150 \%$ when the normal shear stress increased from $50 \mathrm{kPa}$ to $150 \mathrm{kPa}$. For the 5\% and $10 \%$ waste tire treated soils, the maximum shear stresses measured by the direct shear test increased by $110 \%$ and $105 \%$ when the normal stress increased from $50 \mathrm{kPa}$ to $150 \mathrm{kPa}$ respectively. The peak uniaxial stress measured by the unconfined compression test increased by $83 \%$ and $98 \%$ as the waste tire treatment increased from $0 \%$ to $10 \%$ for both testing rates of $0.125 \mathrm{~mm} / \mathrm{min}$ and 0.25 $\mathrm{mm} / \mathrm{min}$ respectively. Finally, finite element method using three different models represented by elastic, hyperbolic and Mohr-Coulomb elastic-plastic models have been used to model unconfined compression tests for both untreated and 10\% waste tire treated soils. For both untreated and waste tire treated soils, the elastic model over predicted the shear stress versus shear strain relationship whereas the elastic-plastic model had a very good agreement with the experimental data. However, the hyperbolic model had a good prediction for the initial part of the shear stress versus shear strain relationship for both untreated and waste tire treated soils with an overestimation for the second part of the experimental data.
\end{abstract}

Keywords: Field Kirkuk Soil; Waste Tire; Direct Shear; Unconfined Compression; Finite Element; Elastic Model; Hyperbolic Model; Mohr-Coulomb.

\section{Introduction}

Waste material is any kind of material that is the output of human and industrial action with no living value. The increasing numbers and categories of waste materials, lack of landfill spaces, and shortage of natural earth materials emphasize on the necessity of discovering advanced ways of reusing and recycling these waste materials [1]. In addition, reutilizing with subsequent reuse of waste materials can decrease the need for natural resources, which can eventually direct to a more sustainable environment [2].

The problem of waste tires is growing daily all over the world. For instance, in the United States, more than 250 million waste tires are stockpiled and currently 5 billion tires are stockpiled [3], and more than 28 million passenger car tires are discarded in Canada [4]. Based on the data of the department of land transport and in the case of Thailand specifically, an accumulated number of registered cars by the 31st of December 2009 was almost 27 million [5]. Thus, if each vehicle needs changing tires every 3 years, then each year the waste tires would approximate 36 million. Considering these enormous numbers, it can be noticed that Thailand and any other country having a similar situation needs to think sensibly about how to manage the waste tires in the near future. In addition, stockpiling of waste scrap tires have the potential of fire hazard leading to environmental harm and a good breeding home for disease-carrying insects and vermin [6]. Hence, finding new and useful ways to reuse and recycle large volumes of waste tires are required. Tire waste can be used as a lightweight material in different forms such as chips, powder, and shredded tires where any type of these forms is used above or below the ground water table [7]. Scrap tires have been used in geotechnical application particularly as embankment materials since scrap tires are cheaper than other alternatives. An estimation of over 13.5 million tons of scrap tires is stockpiled of every single year worldwide [8]. Placing 15 to $30 \mathrm{~cm}$ of shredded waste tires can preserve the subgrade soil from thawing in spring. In addition, the waste tires have a high permeability that allows draining the water from beneath the roads avoiding the road surface damage.

The tire chips are generally between $12 \mathrm{~mm}$ to $50 \mathrm{~mm}$ in size whereas tire shreds are larger [3]. The specific gravity of tire chips and tire shreds varies from 1.02 to 1.26 depending on the quantity of steel belt in the tire [8-10].

Waste tires products represented by tire shreds, tire bales, crumb and ground rubber is used in a variety of engineering purposes such as embankments, backfills, subgrades, erosion control, and asphalt mixture design [11-17]. The waste tire maintains a high damping characteristic that has the benefit to be used in the embankment and railroad track to decrease the disturbance of close by residents [10-18].

Ahmed [9] performed several triaxial tests on tire chips mixed with Ottawa sand and found that the apparent cohesion increases while friction angle decreases with increasing tire chips in the mix. Adding $25 \%$ of the tire chips to sand with size ranges from $20 \mathrm{~mm}$ to $80 \mathrm{~mm}$ increases the shear strength (obtained from direct shear test) slightly at low normal stresses [10]. Foose et al. [8] conducted a study on sand reinforced with shredded waste tires with sizes of $6 \mathrm{~mm}$ to $50 \mathrm{~mm}$ in direct shear test and revealed that Mohr strength envelopes were non-linear and were affected by 
shred contents, normal stress and sand matrix unit weight. It was observed from the stress-strain relationship of a mixture of sand and tire chips that the dilatancy behavior of rubber sand is in between pure sand and pure chips [3].

Triaxial compression tests on sand tire mixture have shown that the shear strength is increased and the compressibility is decreased when there is an increase in the proportion of tire chips or the density [6]. Ghazavi and Sakhi [19] revealed that the affecting parameters on the shear strength characteristics of the sand-shred mixture are sand matrix unit weight, normal stress, shred width, shred content, and aspect ratio of tire shreds. It was reported that initial stiffness decreases with increasing tire chip content in the mixture and increases linearly with the confining pressure [20]. In addition, scrap tires could be used as cushions around building to absorb the vibrating energy generated by an earthquake [21].

Waste tires have been a serious problem facing the entire world for the last 20 to 30 years. By some estimation, Kirkuk city damps a very high percentage of waste tires with no reusing or recycling. Around the world, several previous studies have been attempted to solve this problem in particular treating the soil with waste tires. No studies have addressed the waste tire problem in Iraq generally and Kirkuk specifically. In addition, all the earlier studies have focused on the experimental aspects with no numerical investigation of the behavior of waste tire treated soil.

The main objective of this study is to check the effectiveness of waste tires on the behavior of field soil obtained from Kirkuk city. Particularly, it is required to measure the effect of waste tires on the shear strength behavior of field soil from Al-Sayada location near the campus of the University of Kirkuk. In addition, finite element analysis has been incorporated using three different models represented by elastic, hyperbolic and Mohr-Coulomb models to study the behavior of untreated and waste treated field soil.

\section{Materials and methods}

1) Site

The soil for the study has been chosen from the University of Kirkuk location at Al-Sayada as shown in Figs. 1 and 2 respectively.

2) Drilling and sampling

The soil was collected from Kirkuk city (University of Kirkuk), which is located in the Kirkuk Governorate at the north of Iraq. The samples were taken from a depth of $0.5 \mathrm{~m}$ below the natural ground level using simple manual tools as shown in Fig. 3. The top layer of soil was removed, and then disturbed samples were obtained and transported to the soil mechanics laboratory of the Civil Engineering Department at the University of Kirkuk.

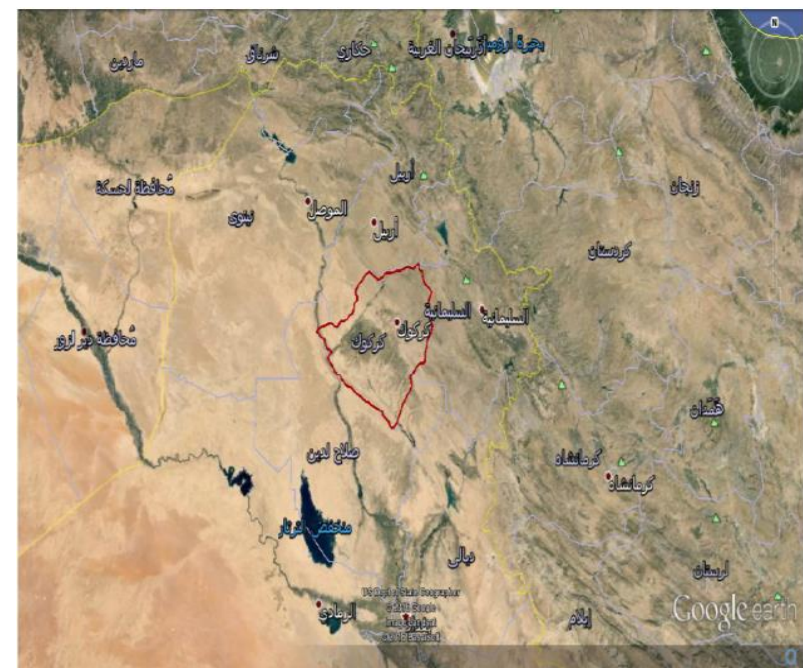

Fig. 1: The Map of Kirkuk City.

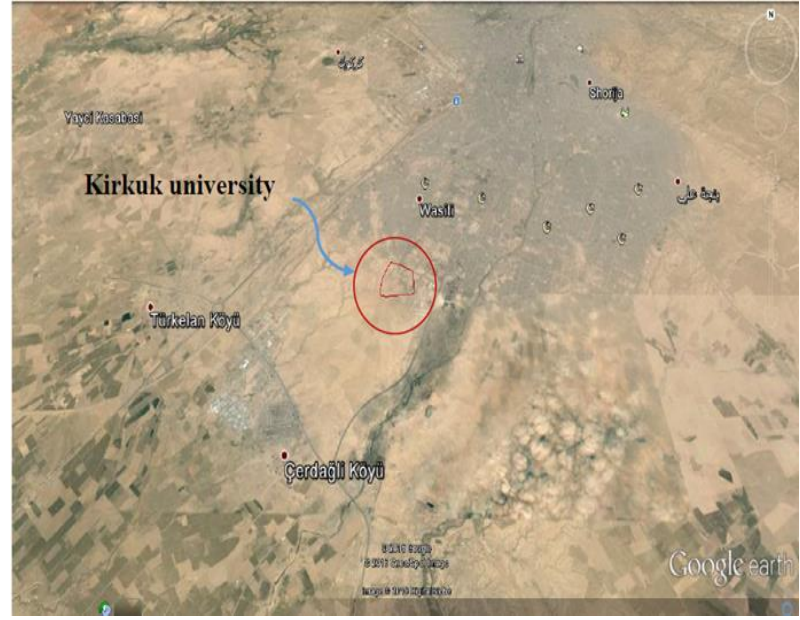

Fig. 2: The Location of the University of Kirkuk.

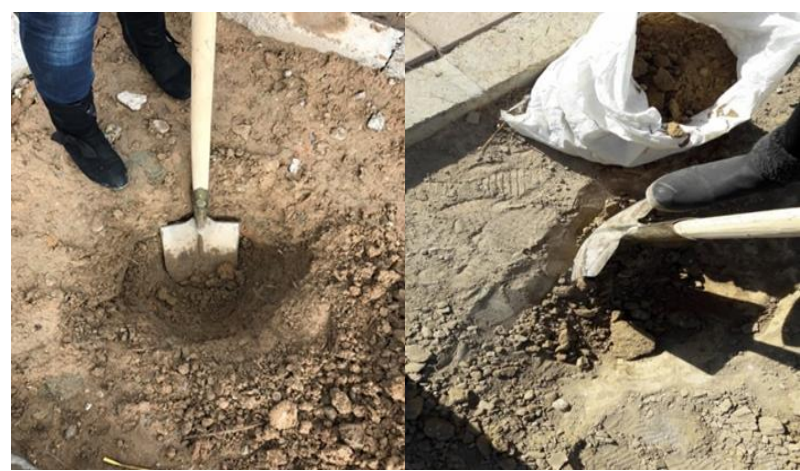

Fig. 3: Disturbed Samples at Depth of 0.5 M below the Ground Level.

3) Laboratory experiments

The water content of the soil samples has been determined according to ASTM 2216 [22]. The specific gravity of the soil was calculated based on the ASTM D854-02 [23]. The particle size distribution of the field soil has been evaluated using ASTM D422-63 [24]. Atterberg limits have been determined according to ASTM D4318-00 [25]. The relationship between water content and dry unit weight was carried out according to ASTM D698-00a [26]. The shear strength of untreated and waste tire treated soils have been tested using direct shear device according to ASTM D3080 [27]. In addition, the unconfined strength of untreated and waste tire treated soils have been performed based on ASTM D2166 [28].

\section{4) Waste tire}

The waste tires have been shredded in very small sizes using mechanical tools in order to make the size of the shredded tires as the same as the particle size of the filed soil. A different percentage of waste shredded tires has been mixed with the field soil and up to $10 \%$ of the total weight of the tested soil samples.

5) Finite element analysis (FEA)

A two dimensional finite element analysis of untreated and waste tire treated field soil have been investigated to verify the experiment test results and understand the deformation of the soil mass where axisymmetric condition was exhibited. The real untreated and waste tire treated soils have been modelled using the data obtained from the laboratory soil experiments. The behaviour of the untreated and tire treated real field soils were simulated using different soil models such as elastic, hyperbolic and elastic-plastic models. The simulation concentrates on modelling the unconfined compression tests performed on both untreated and tire treated field soils.

The simplest used soil model is the linear elastic model where the stresses are directly proportional to the strains. The proportionality constants are both Young's Modulus "E" and Poisson's Ratio "v". The hyperbolic model is used to model the nonlinear elastic stressstrain behaviour of the materials. It provides an adequate prediction of the soil at fairly low shear stress levels. The hyperbolic model is developed in the manner that the soil stiffness increases 
with increasing confining pressure and decreases with increasing shear stress level. The soil stiffness exhibits a very low value at the failure. Duncan et al. [29] proposed the hyperbolic model that used to validate the nonlinear elastic model with a reasonably representative for the soil behaviour. The hyperbolic model parameters can be determined using triaxial compression tests. The hyperbolic model cannot model neither the strain softening behaviour nor plastic failure. In addition, the hyperbolic model cannot characterize the dilatant behaviour or the lateral compression and axial extension.

Based on the hyperbolic model, the deviatoric stress $\left(\sigma_{1}-\sigma_{3}\right)$ is related to axial strain $\varepsilon$ as follows:

$$
\left(\sigma_{1}-\sigma_{3}\right)=\varepsilon /\left(1 / \mathrm{E}_{\mathrm{i}}+\varepsilon /\left(\sigma_{1}-\sigma_{3}\right)_{\mathrm{ult}}\right)
$$

where $\left(\sigma_{1}-\sigma_{3}\right)_{\text {ult }}=$ ultimate (asymptotic) value of deviatoric stress; and $E_{\mathrm{i}}=$ initial tangent Young's modulus. The ultimate deviatoric stress is related to the deviatoric stress at "failure" (soil strength) through:

$$
\left(\sigma_{1}-\sigma_{3}\right) \mathrm{f}=\mathrm{R}_{\mathrm{f}}\left(\sigma_{1}-\sigma_{3}\right) \mathrm{ult}
$$

Where

$\mathrm{R}_{\mathrm{f}}=$ failure ratio, a value typically between 0.5 and 0.9 . Soil strength can be related to confining stress through the MohrCoulomb yield criterion:

$$
\left(\sigma_{1}-\sigma_{3}\right)_{\mathrm{f}}=\left(2 \mathrm{c} \cos \emptyset+2 \sigma_{3} \sin \emptyset\right) /(1-\sin \emptyset)
$$

Where $\mathrm{c}=$ soil cohesive intercept; $\phi=$ soil friction angle; and $\sigma_{3}=$ minor principal stress, which is related to the confining stress imposed on the soil. The failure envelope is considered to be curved by proposing another parameter $\Delta \phi$, which is the change in friction angle because of an increase in $\sigma_{3}$.

The initial tangent modulus is proportional to the confining stress according to:

$$
\mathrm{Ei}=\mathrm{KPa}\left(\sigma_{3} / \mathrm{Pa}\right)^{\mathrm{n}}
$$

Where $\mathrm{K}=$ modulus number, $\mathrm{n}=$ modulus exponent, and $\mathrm{P}_{\mathrm{a}}=$ reference stress (numerically equal to the atmospheric pressure) in the desired units for Ei. By differentiating both equations (1) and (4), the tangent modulus can be given as:

$$
\mathrm{E}_{\mathrm{i}}=\left[1-\left(\mathrm{R}_{\mathrm{f}}(1-\sin \emptyset)\left(\sigma_{1}-\sigma_{3}\right)\right) /\left(2 \mathrm{c} \cdot \cos \emptyset+2 \sigma_{3} \sin \emptyset\right)\right] 2 \mathrm{KP}_{\mathrm{a}}\left(\sigma_{3} / \mathrm{P}_{\mathrm{a}}\right)^{\mathrm{n}}
$$

In this study, an elastic-plastic Mohr-Coulomb model was selected to represent the non-linear behavior of the untreated and tire treated field soils. The limiting states of the stresses are defined by means of the soil undrained shear strength. The initial stresses of the soil were generated using Jaky's formula which defines the at rest earth pressure coefficient $\left(\mathrm{K}_{\mathrm{o}}=1-\sin \phi\right)$ where $\phi$ is the friction angle in terms of total stress.

In the finite element modeling, an axisymmetric condition for a soil sample size of $5.5 \mathrm{~cm}$ diameter and $11 \mathrm{~cm}$ height with 8noded quadrilateral elements having total number of elements equal to 33 , total number of nodes equal to 128 and average element size of $1 \mathrm{~mm}$ have been used. The boundary conditions were chosen where the vertical boundaries are constrained horizontally and free vertically while the bottom horizontal boundary is fully fixed. Loading was applied in very small increments up to the total

\begin{tabular}{|c|c|c|c|}
\hline \multirow{7}{*}{$\begin{array}{l}\text { Hyperbolic } \\
\text { (Nonlinear- } \\
\text { Elastic) }\end{array}$} & Unit weight $\left(\mathrm{kN} / \mathrm{m}^{3}\right)$ & 20 & 19 \\
\hline & $\begin{array}{l}\text { Young's modulus, E } \\
\left(\mathrm{kN} / \mathrm{m}^{2}\right)\end{array}$ & 5000 & 15000 \\
\hline & Poisson's ratio, $\mathrm{v}$ & 0.4 & 0.4 \\
\hline & Cohesion $\left(\mathrm{kN} / \mathrm{m}^{2}\right)$ & 10 & 15 \\
\hline & $\begin{array}{l}\text { Angle of internal } \\
\text { friction, } \Phi^{\circ}\end{array}$ & 25 & 30 \\
\hline & Failure ratio, $\mathrm{R}_{\mathrm{f}}$ & 0.7 & 0.7 \\
\hline & Unit weight $\left(\mathrm{kN} / \mathrm{m}^{3}\right)$ & 20 & 19 \\
\hline \multirow{5}{*}{$\begin{array}{l}\text { Elastic-Plastic } \\
\text { (Mohr- } \\
\text { Coulomb) }\end{array}$} & $\begin{array}{l}\text { Young's modulus, E } \\
\left(\mathrm{kN} / \mathrm{m}^{2}\right)\end{array}$ & 5000 & 15000 \\
\hline & Poisson's ratio, $\mathrm{v}$ & 0.4 & 0.4 \\
\hline & Cohesion $\left(\mathrm{kN} / \mathrm{m}^{2}\right)$ & 10 & 15 \\
\hline & $\begin{array}{l}\text { Angle of internal } \\
\text { friction, } \Phi^{\circ}\end{array}$ & 25 & 30 \\
\hline & Dilation angle, $\psi^{\circ}$ & 20 & 20 \\
\hline
\end{tabular}
load. Values of soil parameters used in this analysis are summarized in Table 1.

Table 1: Soil Parameters for Finite Element Analysis

\begin{tabular}{llll}
\hline \multirow{2}{*}{ Model } & Properties & $\begin{array}{l}\text { Untreated field } \\
\text { soil }\end{array}$ & $\begin{array}{l}\text { Tire treated } \\
\text { soil }\end{array}$ \\
\hline \multirow{3}{*}{ Linear-Elastic } & Unit weight $\left(\mathrm{kN} / \mathrm{m}^{3}\right)$ & 20 & 19 \\
& $\begin{array}{l}\text { Young's modulus, E } \\
\left(\mathrm{kN} / \mathrm{m}^{2}\right)\end{array}$ & 5000 & 15000 \\
& Poisson's ratio, v & 0.4 & 0.4 \\
\hline
\end{tabular}

\section{Results and analysis}

1) Physical soil properties

The collected field soil samples have been tested in the laboratory and the results are summarized in Table 2 . In addition, the particle size distribution of field soil has been shown in Fig. 4. The liquid limit evaluation is shown in Fig. 5. The soils can be classified as clayey sands "sand-clay mixtures" (SC) according to USCS (unified soil classification system). The compaction curve for the tested field soil have been presented in Fig. 6. The maximum and minimum dry densities for the tested field soil were $1.6 \mathrm{gm} / \mathrm{cm}^{3}$ and $2.0 \mathrm{gm} / \mathrm{cm}^{3}$ respectively, whereas the optimum moisture content was $21 \%$.

Table 2: Physical Soil Properties

\begin{tabular}{ll}
\multicolumn{2}{c}{ Table 2: Physical Soil Properties } \\
\hline Property & Value \\
\hline Water content & $8.4 \%$ \\
Specific gravity & 2.68 \\
Effective size, $\mathrm{D}_{10}$ & $0.1 \mathrm{~mm}$ \\
Coefficient of uniformity, $\mathrm{C}_{\mathrm{u}}$ & 11.8 \\
Coefficient of curvature, $\mathrm{C}_{\mathrm{c}}$ & 0.76 \\
Liquid limit & 23.9 \\
Plastic limit & 4.9 \\
\hline
\end{tabular}

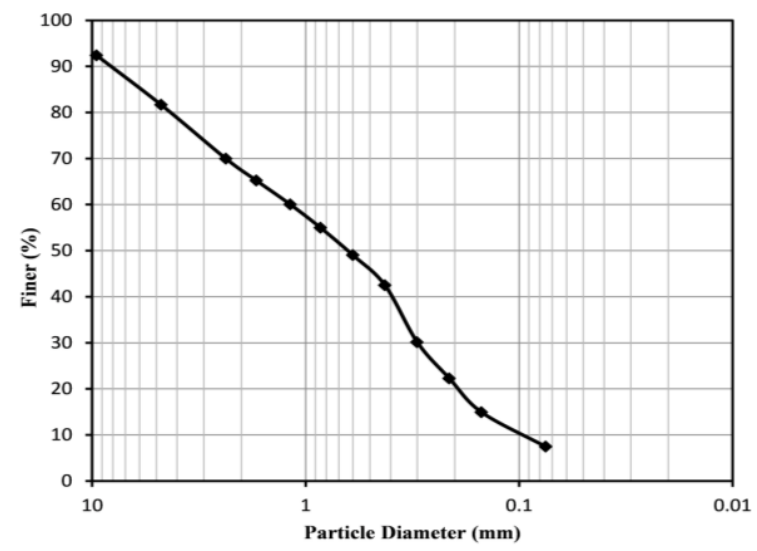

Fig. 4: Grain Size Distribution of the Field Soil.

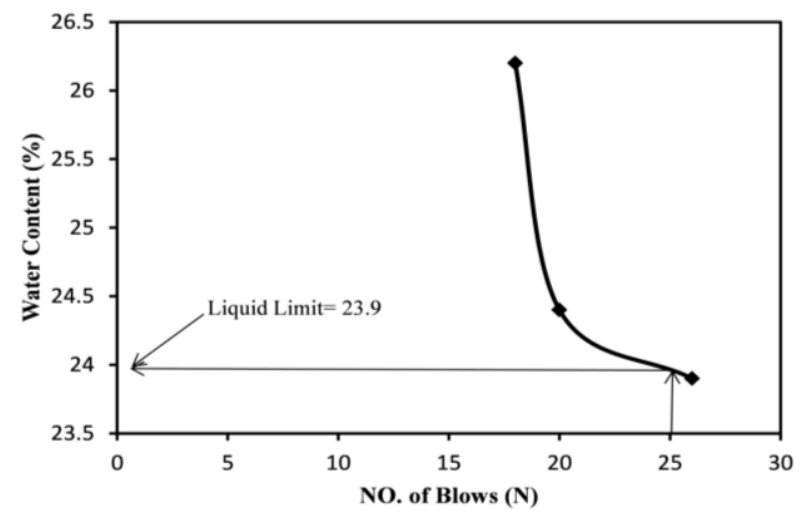

Fig. 5: Liquid Limit Evaluation. 


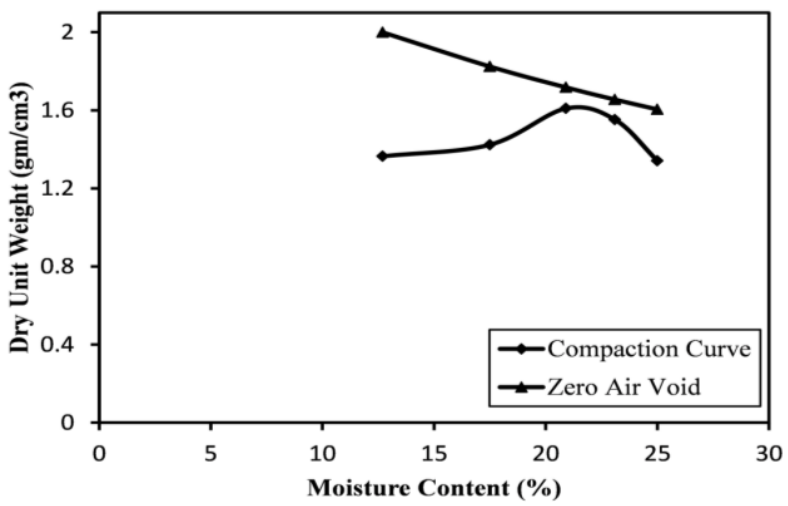

Fig. 6: The Compaction Curve for the Tested Field Soil.

2) Direct shear results

The shear stress variation with the horizontal displacement for different applied normal stress for untreated and waste tire treated soils is shown in Fig. 7. It is clearly shown that the shear stress increases with increasing the normal stress for both untreated and treated field soils and up to $10 \%$ waste tire treatment. For the untreated soil, the maximum shear stress increased by $150 \%$ when the normal shear stress increased from $50 \mathrm{kPa}$ to $150 \mathrm{kPa}$. For the $5 \%$ waste tire treated soil, the maximum shear stress increased by $110 \%$ when the normal stress increased from $50 \mathrm{kPa}$ to $150 \mathrm{kPa}$. For the $10 \%$ waste tire treated soil, the maximum shear stress increased by $105 \%$ when the normal stress increased from $50 \mathrm{kPa}$ to $150 \mathrm{kPa}$. Applying higher normal stresses on both untreated and waste tire treated soils increase the shear stress since the particles become closer leading to higher tangential stresses.

The shear stress variation with the horizontal displacement for the same applied normal stress of untreated and waste tire treated soils is shown in Fig. 8. For the applied normal stress of $50 \mathrm{kPa}$, the maximum shear stress increased by $67 \%$ when the waste tire treatment increased from $0 \%$ to $10 \%$. For the applied normal stress of $100 \mathrm{kPa}$, the maximum shear stress increased by $119 \%$ when the waste tire treatment increased from $0 \%$ to $10 \%$. For the applied normal stress of $150 \mathrm{kPa}$, the maximum shear stress increased by $36 \%$ when the waste tire treatment increased from $0 \%$ to $10 \%$. It is effectively shown that the waste tire has the ability to increase the shear strength (maximum shear stress) of the field soil with the maximum impact of $119 \%$ when the applied normal stress and waste tire treatment are $100 \mathrm{kPa}$ and $10 \%$ respectively.

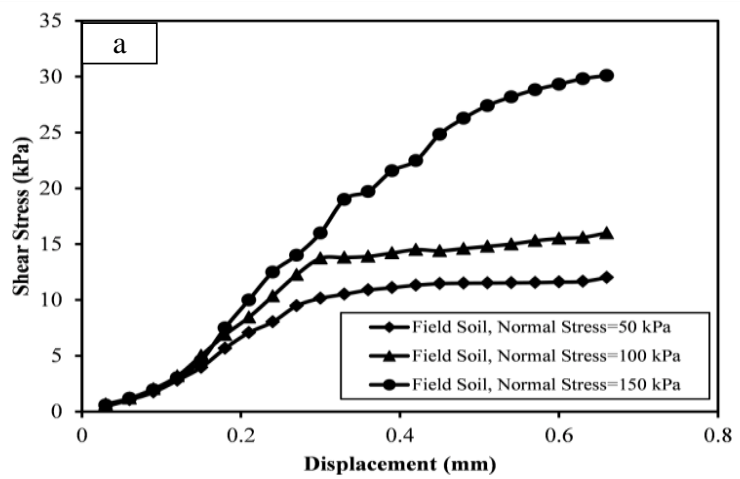

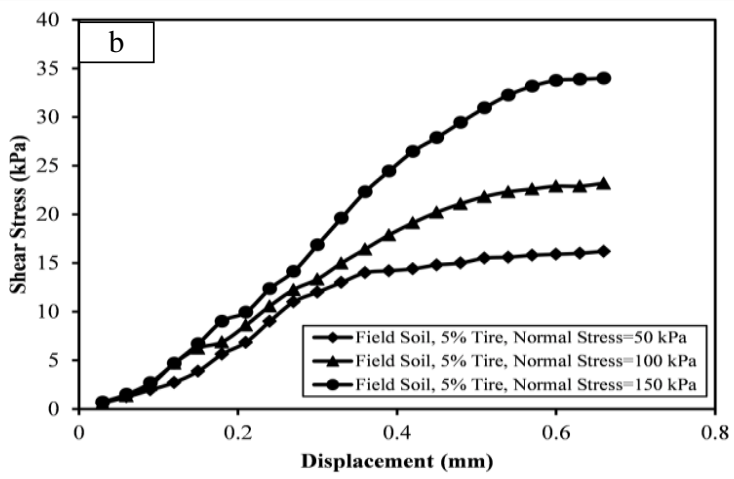

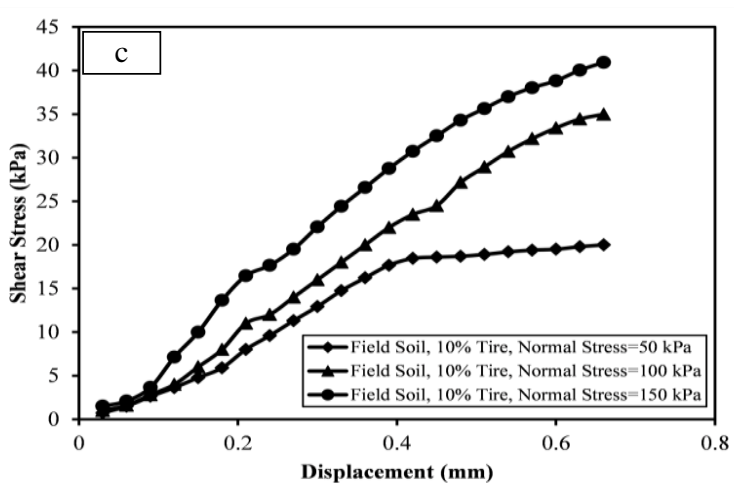

Fig. 7: The Variation of the Shear Stress With the Horizontal Displacement for the Untreated and Waste Tire Treated Soils with Different Applied Normal Stresses of (A) $0 \%$ Waste Tire Treatment, (B) 5\% Waste Tire Treatment, and (C) 10\% Waste Tire Treatment.
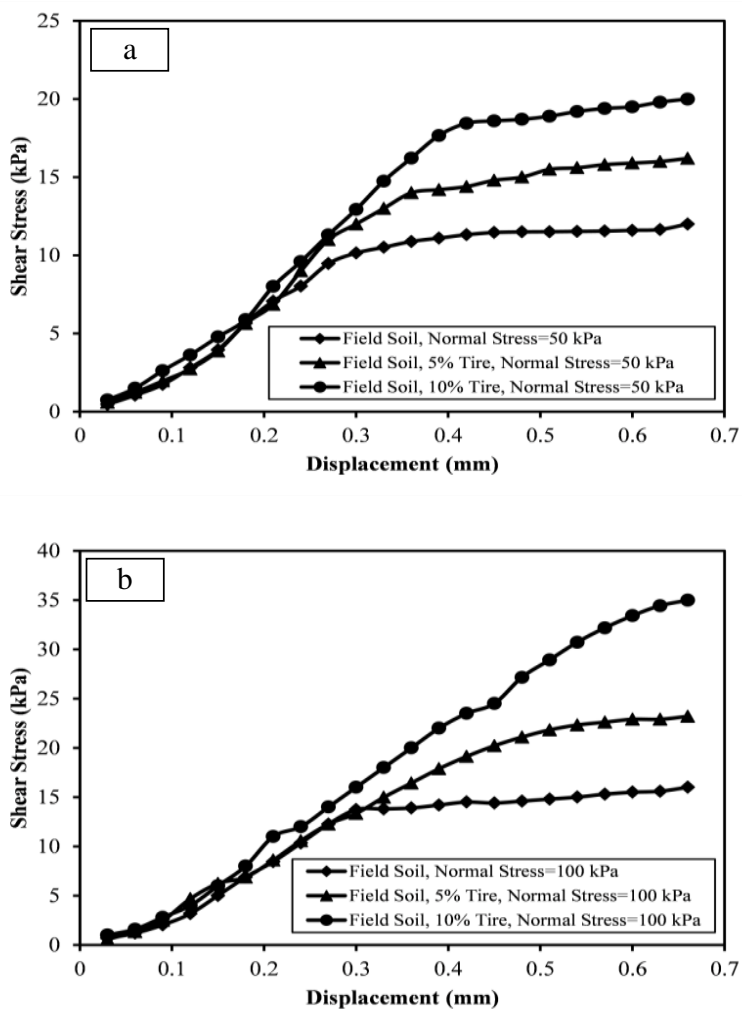


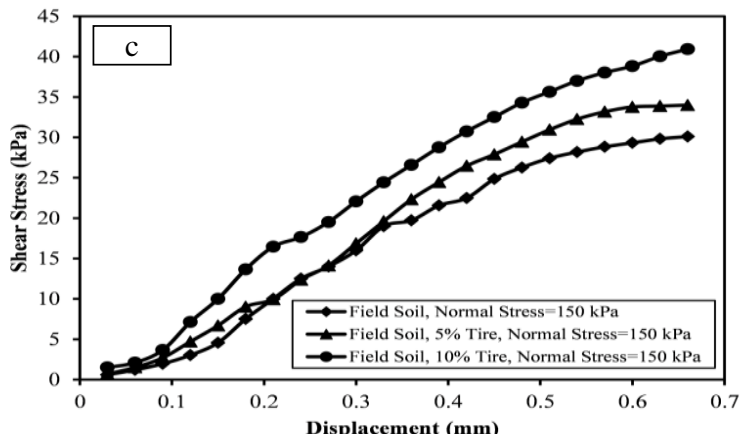

Fig. 8: The Variation of the Shear Stress with the Horizontal Displacement for the Untreated and Waste Tire Treated Soils with Different Applied Normal Stresses of (A) Normal Applies Stress $=50 \mathrm{Kpa}$, (B) Normal Applies Stress $=100 \mathrm{Kpa}$, And (C) Normal Applies Stress $=150 \mathrm{Kpa}$.

3) Unconfined compression results

The variation of the uniaxial compression stress with the vertical strain for untreated and waste tire treated field soils tested under different rates are shown in Fig. 9. The uniaxial stress increased with increasing the vertical strain up to the peak value then started to decrease up to the failure. The peak uniaxial stress increased by $83 \%$ and $98 \%$ as the waste tire treatment increased from $0 \%$ to $10 \%$ for both testing rates of $0.125 \mathrm{~mm} / \mathrm{min}$ and $0.25 \mathrm{~mm} / \mathrm{min}$ respectively. The peak uniaxial stresses were $23 \mathrm{kPa}$ and $42 \mathrm{kPa}$ for $0 \%$ and $10 \%$ waste tire treatment at a testing rate of 0.125 $\mathrm{mm} / \mathrm{min}$ whereas the peak uniaxial stresses were $16.1 \mathrm{kPa}$ and $31.9 \mathrm{kPa}$ for $0 \%$ and $10 \%$ waste tire treatment at a testing rate of $0.25 \mathrm{~mm} / \mathrm{min}$. Hence, it is clearly indicated that the lower testing rate has given higher peak uniaxial stress for both untreated and waste tire treated field soils. For the both testing rates of 0.125 $\mathrm{mm} / \mathrm{min}$ and $0.25 \mathrm{~mm} / \mathrm{min}$, the peak uniaxial stresses occurred at a strain range of $0.5 \%$ to $0.65 \%$.

The failure patterns of the untreated and waste tire treated soils for the unconfined compression tests have shown in Fig. 10. It has noticed that the untreated and waste tire treated soils follow different failure patterns where the waste tire strengthen the core of the soils compared to the untreated soils.
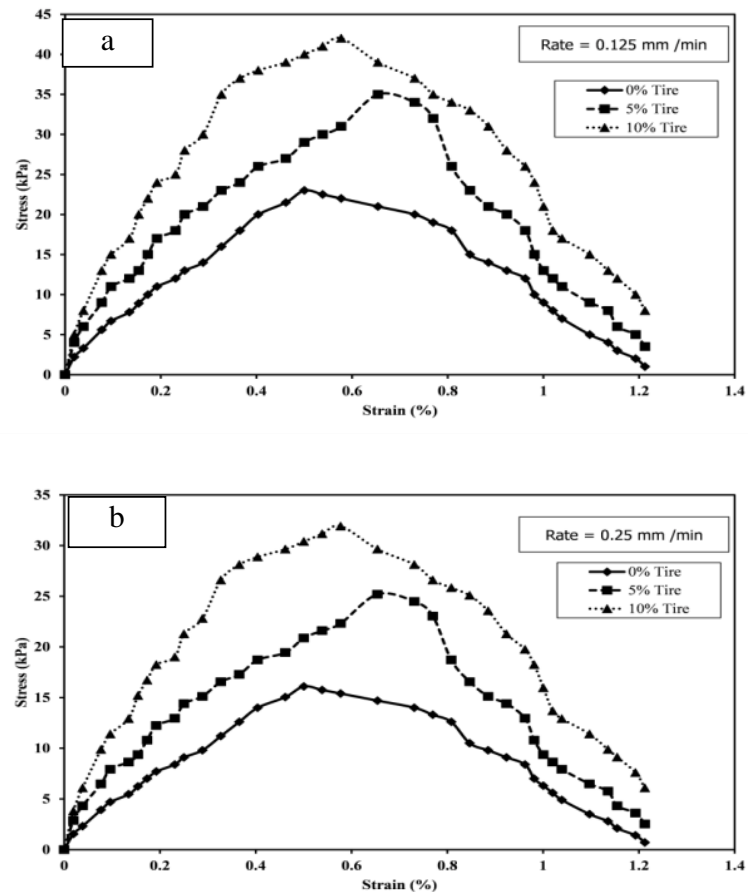

Fig. 9: The Variation of the Uniaxial Stress with the Vertical Strain for the Untreated and Waste Tire Treated Soils with Different Testing Rates of (A) Testing Rate $=0.125 \mathrm{Mm} / \mathrm{Min}$, and (B) Testing Rate $=0.25 \mathrm{Mm} / \mathrm{Min}$.

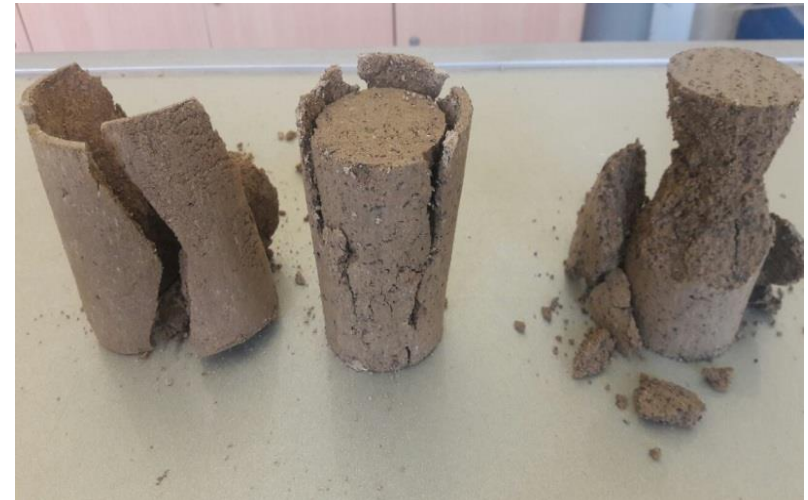

Fig. 10: The Failure Pattern of the Untreated and Waste Tire Treated Soils in the Unconfined Compression Test.

4) Finite elements results

a) Deformed Mesh

(A)

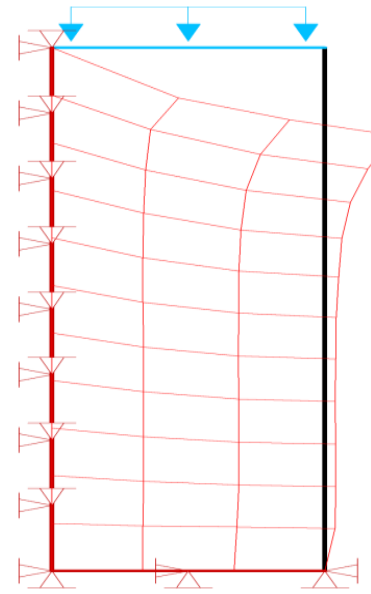

(B)

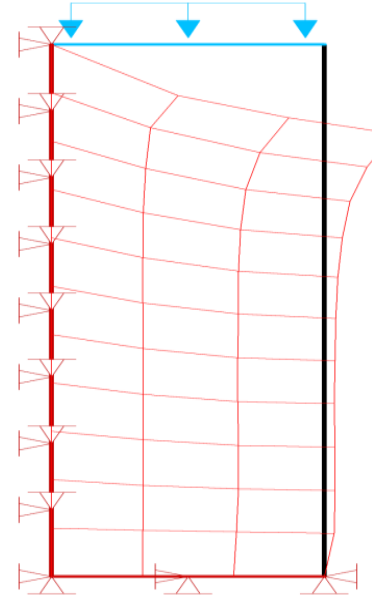

Fig. 11: The Deformed Mesh for Unconfined Compression Test Using Elastic Model for (A) Untreated Soil, and (B) 10\% Waste Tire Treated Soil.

The deformed mesh for unconfined compression test using the elastic model for both untreated and $10 \%$ waste tire treated soils have shown in Fig. 11. When the elastic model is used, both untreated and waste tire treated soils exhibited similar deformed shapes. 
(A)

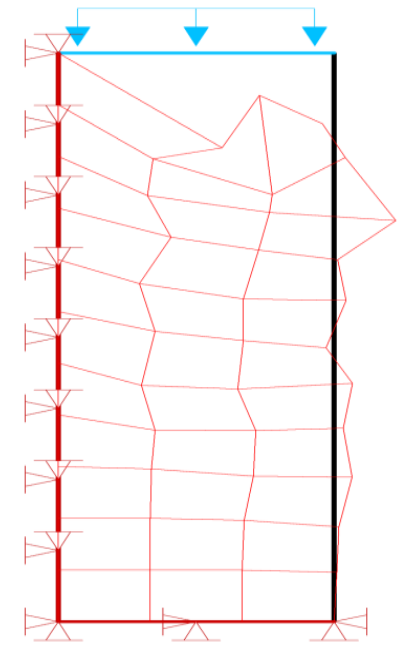

(B)

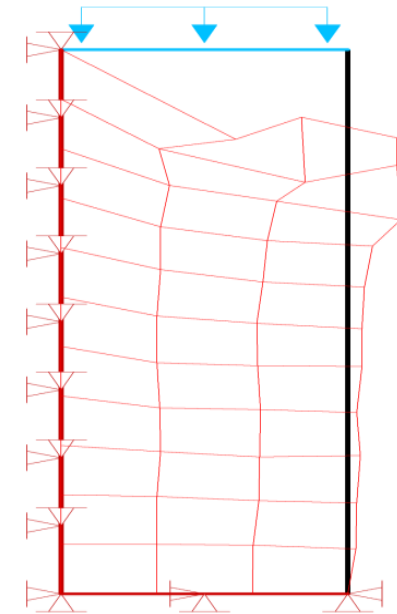

Fig. 12: The Deformed Mesh for Unconfined Compression Test Using Hyperbolic Model for (A) Untreated Soil, and (B) 10\% Waste Tire Treated Soil.

In addition, the deformed mesh for unconfined compression test using the elastic-plastic model for both untreated and $10 \%$ waste tire treated soils have shown in Fig. 13. When the elastic-plastic model is used, both untreated and waste tire treated soils adopted similar deformed shapes.

(A)

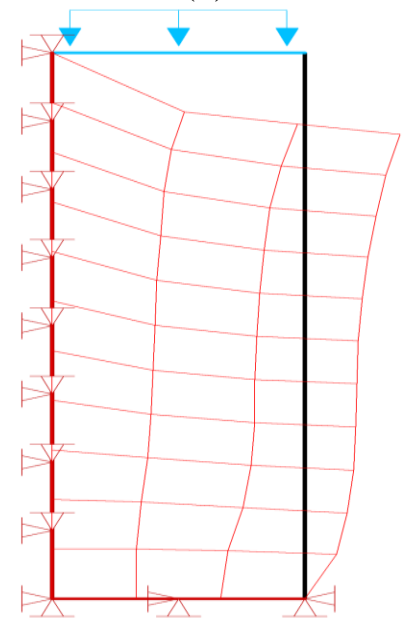

(B)

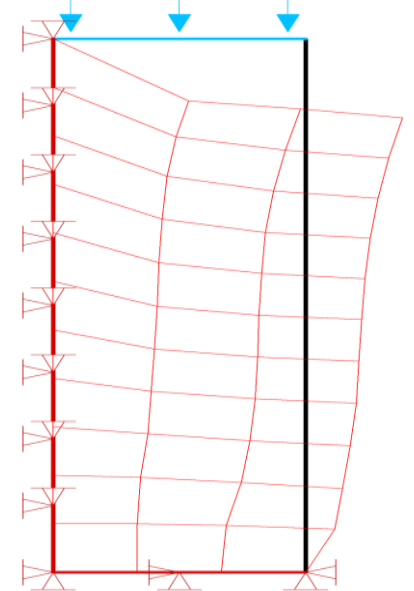

Fig. 13: The Deformed Mesh for Unconfined Compression Test Using Elastic-Plastic Model for (A) Untreated Soil, and (B) $10 \%$ Waste Tire Treated Soil.

b) Shear stress-shear strain

The finite element method has been used to predict the shear stress versus shear strain relationship for unconfined compression test using elastic, hyperbolic and elastic-plastic models for both untreated and 10\% waste tire treated soil as shown in Figs. 14 and 15 respectively. For both untreated and waste tire treated soils, the elastic model over predicted the shear stress versus shear strain relationship whereas the elastic-plastic model had a very good agreement with the experimental data. For both untreated and waste tire treated soils, the hyperbolic model had a good prediction for the initial part of the shear stress versus shear strain relationship with an overestimation for the second part of the experimental data.

c) Maximum vertical displacement-time

The variation of the maximum vertical displacement with the time for both untreated and $10 \%$ waste tire treated soils were predicted using finite element method with three different models as shown in Figs. 16 and 17 respectively. For both untreated and waste tire treated soils, the elastic model underestimated the maximum vertical displacement versus time relationship whereas the elasticplastic model had a very good agreement with the experimental data. For the untreated soil, the hyperbolic model has predicted the early initial part of the experimental data well with an overestimation for the rest of the experimental data. For the $10 \%$ waste tire treated soil, the hyperbolic model has underestimated most of the experimental data with a good agreement with the final experimental value.

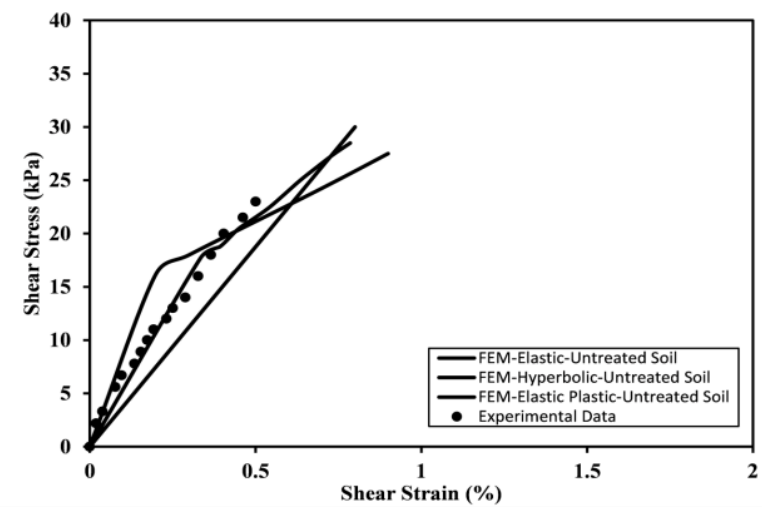

Fig. 14: Comparison between Finite Element Predictions with Experimental Data for the Shear Stress-Shear Strain Relationship of Untreated Soil Using Three Different Models. 


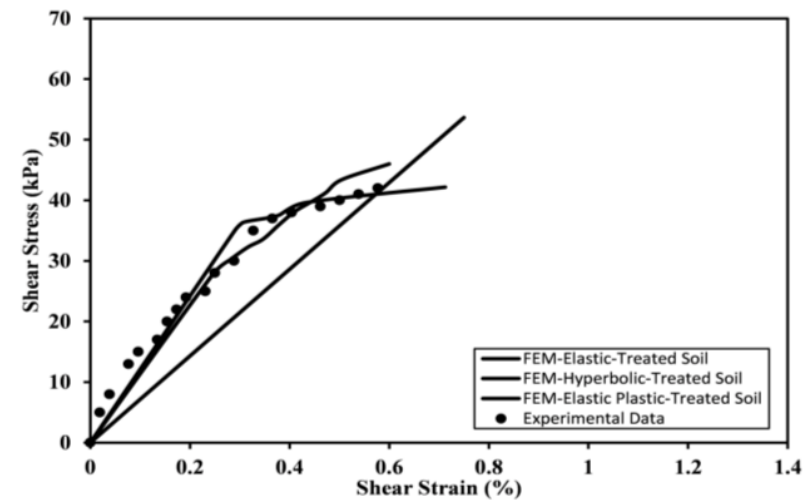

Fig. 15: Comparison between Finite Element Predictions with Experimental Data for the Shear Stress-Shear Strain Relationship of 10\% Waste Tire Treated Soil Using Three Different Models.

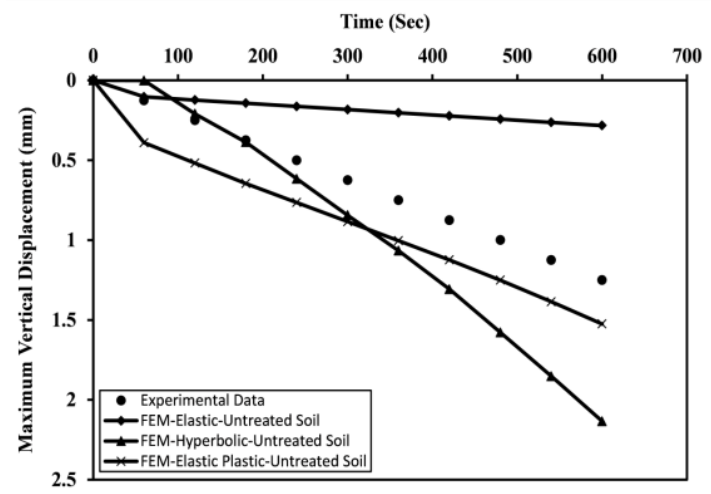

Fig. 16: Comparison between Finite Element Predictions with Experimental Data for the Maximum Vertical Displacement Relationship of Untreated Soil Using Three Different Models.

d) Maximum horizontal displacement-time

The variation of the maximum horizontal displacement with the time for both untreated and $10 \%$ waste tire treated soils have been predicted using finite element method with three different models as shown in Figs. 18 and 19 respectively. For both untreated and waste tire treated soils, the elastic and hyperbolic models overestimated the maximum horizontal displacement versus time relationships whereas the elastic model had a good agreement with the experimental data.

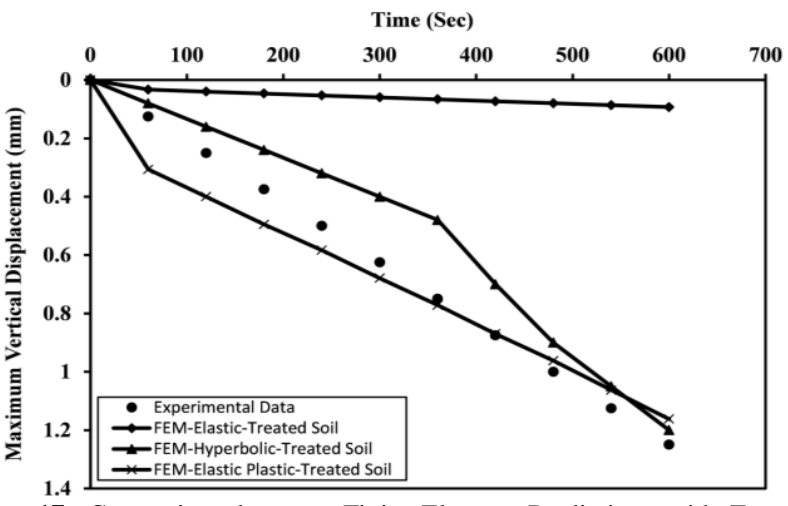

Fig. 17: Comparison between Finite Element Predictions with Experimental Data for the Maximum Vertical Displacement Relationship of $10 \%$ Waste Tire Treated Soil Using Three Different Models.

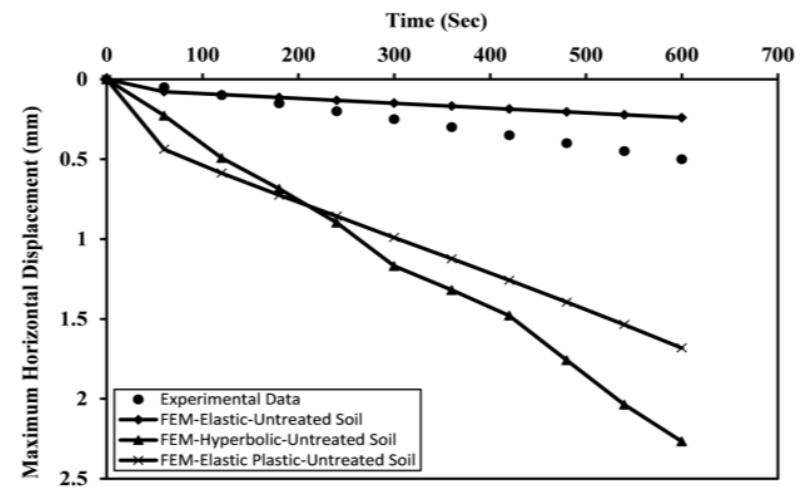

Fig. 18: Comparison between Finite Element Predictions with Experimental Data for the Maximum Horizontal Displacement Relationship of Untreated Soil Using Three Different Models.

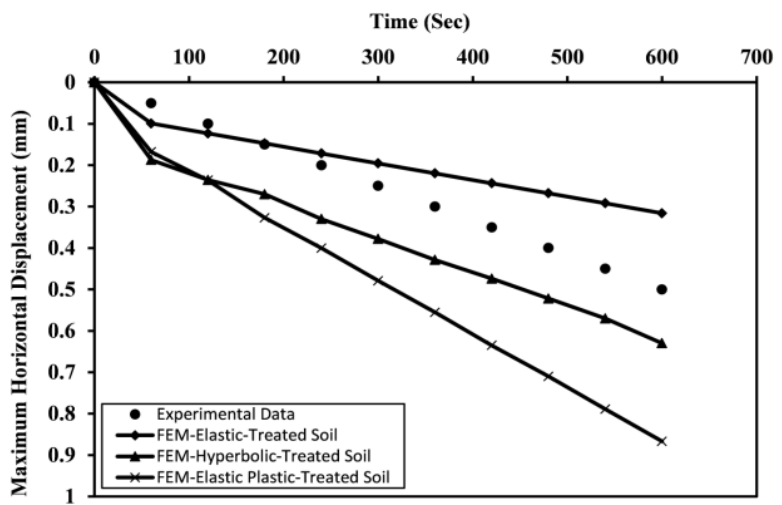

Fig. 19: Comparison between Finite Element Predictions with Experimental Data for the Maximum Horizontal Displacement Relationship of 10\% Waste Tire Treated Soil Using Three Different Models.

\section{Conclusions}

Based on the experimental and numerical results of this study, the following conclusions can be drawn:

1) The grain size distribution of the Kirkuk field soil has shown that the soil can be classified as sand-clay mixtures with maximum and minimum dry densities of $1.6 \mathrm{gm} / \mathrm{cm}^{3}$ and $2.0 \mathrm{gm} / \mathrm{cm}^{3}$ respectively.

2) For the untreated field soil, the maximum shear stress obtained from direct shear tests increased by $150 \%$ when the normal shear stress increased from $50 \mathrm{kPa}$ to $150 \mathrm{kPa}$. For the $5 \%$ and $10 \%$ waste tire treated soils, the shear stress measured from direct shear tests increased by $110 \%$ and $105 \%$ when the normal stress increased from $50 \mathrm{kPa}$ to 150 $\mathrm{kPa}$ respectively.

3) It is remarkably shown that the waste tire has the ability to increase the shear strength of the field soil with the maximum impact of $119 \%$ when the applied normal stress of the direct shear test was $100 \mathrm{kPa}$ at $10 \%$ waste tire treatment.

4) The peak uniaxial stress obtained from unconfined compression test increased by $83 \%$ and $98 \%$ as the waste tire treatment increased from $0 \%$ to $10 \%$ for both testing rates of $0.125 \mathrm{~mm} / \mathrm{min}$ and $0.25 \mathrm{~mm} / \mathrm{min}$ respectively.

5) It is clearly shown that the lower testing rate of the unconfined compression test has given higher peak uniaxial stress for both untreated and waste tire treated field soils.

6) Both untreated and waste tire treated soils exhibited similar deformed shapes when elastic or elastic-plastic models are used. However, the upper zone for the untreated soil is affected more that the upper zone for $10 \%$ waste tire treated soils when the hyperbolic model is used.

7) For both untreated and waste tire treated soils, the elastic model over predicted the shear stress versus shear strain relationship whereas the elastic-plastic model had a very good agreement with the experimental data. However, the hyper- 
bolic model had a good prediction for the initial part of the shear stress versus shear strain relationships with an overestimation for the second part of the experimental data.

8) For both untreated and waste tire treated soils, the elastic model underestimated the maximum vertical displacement versus time relationship whereas the elastic-plastic model had a very good agreement with the experimental data.

9) For both untreated and waste tire treated soils, the elastic and hyperbolic models overestimated the maximum horizontal displacement versus time relationships whereas the elastic model had a good agreement with the experimental data.

\section{Acknowledgements}

The author would like to thank all the staff at the Geotechnical Laboratory in the Civil Engineering Department at the University of Kirkuk

\section{References}

[1] Lepcha K. H., Agnihotri A. K., Priyadarshee A., Yadav M. (2014) "Application of tire chips in reinforcement of soil: a review," Journal of Civil Engineering and Environmental Technology, 1(5), pp. 51-53.

[2] Chen H., Wong Q. (2006). "The behavior of soft soil stabilizationnusing cement," Bulletin of Engineering Geology and the Environmenta by Springerlink.

[3] Lee J.H., Salgado R., Bernal A., Lovell C.W. (1999). "Shredded tires and rubber-sand as lightweight backfill," J Geotech Geoenviron Engrg, ASCE, 125(2), pp. 132-41. https://doi.org/10.1061/(ASCE)1090-0241(1999)125:2(132).

[4] Garga V.K., O'Shaughnessy V. (2000). "Tire-reinforced earth fill, part 1: construction of a test fill, performance and retaining wall design," Canadian Geotechnical Journal, 37, pp. 75-96. https://doi.org/10.1139/t99-084.

[5] Promputthangkoon P., Hyde A.F.L. (2010). "Liquefaction mitigation by means of sand tyre chip mixtures," 17th SEAGC, Taiwan, pp. 371- 374.

[6] Youwai S., Bergado D.T. (2004). "Numerical analysis of reinforced wall using rubber tire chips-sand mixtures as backfill material,' Computers and Geotechnics, 31, pp. 103-114. https://doi.org/10.1016/j.compgeo.2004.01.008.

[7] Ayothiraman R., Abilash M. (2011). "Improvement of subgrade soil with shredded waste tyre chips," Proceedings of Indian Geotechnical Conference Kochi, Paper no H -033, pp. 365-368.

[8] Foose G.J., Benson C.H., Bosscher P.J. (1996). "Sand reinforced with shredded waste tires," Journal of Geotechnical Engineering, 122(9), pp.760-767. https://doi.org/10.1061/(ASCE)07339410(1996)122:9(760)

[9] Ahmed I. (1993). "Laboratory study on properties of rubber soils," Report No. FHWA/IN/JHRP - 93/4, Purdue University, West Lafayette, IN.

[10] Edil T.B., Bosscher P.J. (1994). "Engineering properties of tire chips and soil mixtures," Geotechnical Testing J., GTJODJ, 17 (4), pp. 453-464.

[11] Ahmed I., Lovell C.W. (1993). "Rubber soils as lightweight geomaterials," Lightweight Artificial and Waste Materials for Embankments over Soft Soils, Transportation Research Record, (1422), National Academy Press, Washington, DC, pp. 61-70.

[12] Upton R.J., and Machan G. (1993). "Use of shredded tires for lightweight fill," Lightweight Artificial and Waste Materials for Embankments over Soft Soils, Transportation Research Record, (1442), National Academy Press, Washington, DC, pp. 36-45.

[13] Newcomb D.E., Drescher A. (1994). "Engineering properties of shredded tires in lightweight fill applications," Transportation Research Record, (1437), National Academy Press, Washington, DC pp. 1-7.

[14] Kershaw D.S., Pamukcu S. (1997). "Use of ground tire rubber in reactive permeable barriers to mitigate btex compounds," Testing Soil Mixed with Waste or Recycled Materials, ASTM STP 1275 , M.A. Wasemillier, K.B. Hoddinott, Eds., ASTM, pp. 314-329. https://doi.org/10.1520/STP15660S.

[15] Edil T.B. (2005). "A review of mechanical and chemical properties of shredded tires and soil mixtures," Recycled Materials in Geotechnics: Proc. of Sessions of the ASCE Civil Engineering Conference and Exposition, ASCE, GSP No. 127, pp. 1-21.
[16] Zornberg J.G., Christopher B.R., Oosterbaan M.D. (2005). "Tire bails in highway applications: feasibility and properties evaluation," Colorado Department of Transportation Research Branch, (CDOTDTD-R-2005-2)

[17] Ashmanwy A., McDonald R., Carreon D., Atalay F. (2006). "Stabilization of marginal soils using recycled materials," Florida Department of Transportation, (BD-544-4).

[18] Feng Z. and Sutter K.G. (2000). "Dynamic properties of granulated rubber/sand mixtures," Geotechnical Testing J., GTJODJ, 23 (3), pp 338-344.

[19] Ghazavi M., Sakhi M.A. (2005).’'Influence of optimized tire shreds on shear strength parameters of sand," International Journal of Geomechanics, 5(1), pp. 58-65. https://doi.org/10.1061/(ASCE)15323641(2005)5:1(58).

[20] Dutta R.K., Rao V. G. (2007).'Regression model for predicting the behavior of sand reinforced with waste plastic," Turkish Journal of Engineering and Environmental Sciences, 31(2), pp. 119-126.

[21] Xu X., Lo S.H., Tsang H.H., Skeikh M.N. (2009). "Earthquake potential by tire-soil mixtures: numerical study," Proceedings for New Zealand Society for Earthquake Engineering Conference.

[22] ASTM 2216. (2016). "Standard Test Method for Laboratory Determination of Water (Moisture) Content of Soil, Rock, and SoilAggregate Mixtures," ASTM International, West Conshohocken, PA.

[23] ASTM D854-02. (2002). "Specific gravity of Soil Solids by Water Pycnometer," ASTM International, West Conshohocken, PA.

[24] ASTM D422-63. (2007). "Particle-size Analysis of Soils," ASTM International, West Conshohocken, PA.

[25] ASTM D4318-00. (2000). "Liquid limit, Plastic limit and Plasticity Index of Soils," ASTM International, West Conshohocken, PA.

[26] ASTM D698-00a. (2000). "Standard Test Methods for Laboratory Compaction Characteristics of Soil Using Standard Effort," ASTM International, West Conshohocken, PA.

[27] ASTM D3080. (2011). "Standard Test Method for Direct Shear Test of Soils under Consolidated Drained Conditions," ASTM International, West Conshohocken, PA.

[28] ASTM D2166. (2016) "Standard Test Method for Unconfined Compressive Strength of Cohesive Soil," ASTM International, West Conshohocken, PA.

[29] Duncan J.M., Wong K.S., Ozawa Y. (1980). "FEDAM: a computer program for finite element analysis of dams," Report $n^{\circ}$ UCB/GT/80-2, College of Engineering, Office of Research Services, University of California, Berkeley. 